\title{
Photoacoustic Detection in the Michelson Interferometer Cavity
}

\author{
Mohammad I. Abu Taha1, Ahmed S. Jabr² \\ ${ }^{1}$ Physics Department, College of Science and Technology, Al-Quds University, Jerusalem, Palestine \\ ${ }^{2}$ The School of Science Research, Al Qusais, Dubai \\ Email: mabutaha@science.alquds.edu, a jabr76@yahoo.com
}

Received 30 December 2013; revised 28 January 2014; accepted 21 February 2014

Copyright (C) 2014 by authors and Scientific Research Publishing Inc.

This work is licensed under the Creative Commons Attribution International License (CC BY).

http://creativecommons.org/licenses/by/4.0/

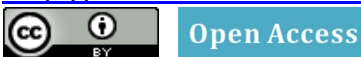

\begin{abstract}
For the first time, we report photoacoustic (PA) signal detection in a cell placed within the Michelson interferometer cavity in an attempt to relate photoacoustic effect to the Michelson fringe shift as a result of changes in the cell. Both detection schemes were investigated using IR absorption and their sensitivities compared. Signals related to Michelson interferometer fringe and PA effect have shown good correlations with each other using different samples including some essential oils and their corresponding plant part from which the essential oil is usually obtained. Results were encouraging and will open the door widely to use the combined Michelson interferometer-photoacoustic spectroscopy (PAS) in trace gas detection for different applications.
\end{abstract}

\section{Keywords}

Michelson Interferometer, Photoacoustic Effect, Photoacoustic Spectroscopy, Trace Gas Detection, Miniature Infrared Source

\section{Introduction}

Photoacoustic (PA) spectroscopy is a version of photothermal spectroscopy in which the absorbed energy is released resulting in a localized pressure wave i.e. sound wave [1]-[10]. This sensitive spectroscopic technique is based on the Bell's discovery of the PA effect in 1880 [11], which has become widely applicable as an investigation method for matter in all its phases [4]. With the aid of powerful $\mathrm{CO}_{2}$ lasers, the PA effect was successfully applied to study traces of different essential oils components within the plant tissues without the necessity for the later to be steam-distilled [12]. PA has showed high capabilities of being an alternative method for simultaneously measuring different photosynthetic parameters like light absorption, oxygen evolution and energy storage over a wide temperature range [13]. Recent studies showed that the technique was successfully applied 
to thermal characterization of ceramic tapes [10] and molecular relaxation effects in hydrogen chloride [14].

Michelson-Morley experiment was performed in 1887 by Albert Michelson and Edward Morley attempting to detect the relative motion of matter through the ether [15]. Later, Michelson interferometer emerged as a useful investigation tool that is based on light beam interference [16]-[20] and its ability in detecting the differences in path lengths between its two arms. This path length difference can show up as a result of changes taking place in a cell placed in one arm of the interferometer. Practically, it was used to measure dimensions, refractive indices, wavelengths and surface roughness [21] and in Fourier transform spectroscopy [22]-[25]. It was also used to study the absorption spectra of gases at high pressures in the range of $10-110 \mathrm{~cm}^{-1}$ [22].

This work is concerned with trace gas detection using (PAS) in conjunction with Michelson interferometer. It is obvious from literature that PAS - mostly carried out with powerful laser sources especially in the IR range, which showed high capabilities in the field of trace gas detection. Contrary, Michelson's interferometry was successfully applied to precise determinations of refractive indices. When both techniques combined together, HeNe laser is used to illuminate the interferometer and to sense the optical changes within the cell. The PA signal is generated following an IR absorption by gases traces of released in the cell. This combination allowed studying the origins of PA and Michelson fringe signals and building up a new detection method based on the combined Michelson-PA cell.

\section{The Combined Michelson-PA Cell Design}

The used cell is a hollow aluminum cylinder of open ends, $3.97 \mathrm{~cm}$ long and $3.60 \mathrm{~cm}$ diameter. The open ends are closed by glass windows fitted with rubber O-rings in order to achieve reasonable sealing of the sample vapors inside the cell. A miniature infrared source is attached to one cell side, opposite to a Helmholtz cell fitted to the opposite cell wall. The Helmholtz cell is consisted of two components; neck and cylindrical cup joined as one unit, it was used to enhance the PA signal level. A sensitive microphone was used to detect the PA signal of the type Knowles Electronics, item number (wz398) and mounted directly on the cylindrical cup constituting the main Helmholtz cavity. This arrangement allows sensitive detection of PA signals resulting from the absorptions of the very low power delivered by the miniature IR source in the range $\sim 20 \mathrm{nW} / \mathrm{cm}^{2}$.

\section{IR Thermal Source}

A pulsed wideband mid-IR thermal source based on electrical heating of a thin metal alloy foil up to red heat $\left(\sim 900^{\circ} \mathrm{C}\right)$ and cooled by its own radiation has been used. The miniature source has a two sided emitting area of 12 $\mathrm{mm}$ diameter bi-spiral filament suspended in such way to offers thermal isolation from the supporting structure. The supporting structure is a $15 \mathrm{~mm}$ long and $5 \mathrm{~mm}$ in diameter ceramic post with four equi-spaced $1 \mathrm{~mm}$ diameter holes threading its length. The source filament is $25 \mu \mathrm{m}$ thick Fecralloy foil composed of four elements constituting certain percentages as follows: Fe $72.6 \%$, Cr 22\%, Al 4.8\%, Si $0.3 \%$, and Y 0.3\% [26]. The source is a wideband IR source, emitting in the range $\sim 0.75-15 \mu \mathrm{m}$ when driven at $\sim 900^{\circ} \mathrm{C}$, looking dull red.

\section{Simultaneous Michelson-PA Signal Detection Scheme}

The IR radiation from the pulsed wideband IR source is allowed to fall on sample, molecules being evaporated inside the cell. The source radiation falls at right angles to the chamber axis along which HeNe beam is passing. The HeNe laser beam is adjusted so interference fringes form on the light photometer. The absorbed IR radiation by the vapor generates heat waves which results in pressure fluctuations and optical changes within the chamber. Pressure fluctuations are amplified in the Helmholtz cell and detected by the sensitive microphone, i.e. as a PA signal. The optical changes in the cell, i.e. index of refraction and modulated pressure change, result in a fringe shift detected by the light photometer as change in light intensity. Figure 1 show the complete experimental set up used in the present study.

\section{Experimental Results and Discussion}

Results of the combined Photoacoustic-Michelson interferometer trace gas detection of natural oils vapors, plant seeds, green plant leaves, and some test chemicals solution were obtained. The system reliability was checked prior to using unknown samples by introducing the trace vapors of Chloroform $\left(\mathrm{CHCl}_{3}\right)$ as a known sample see Figure 2. 


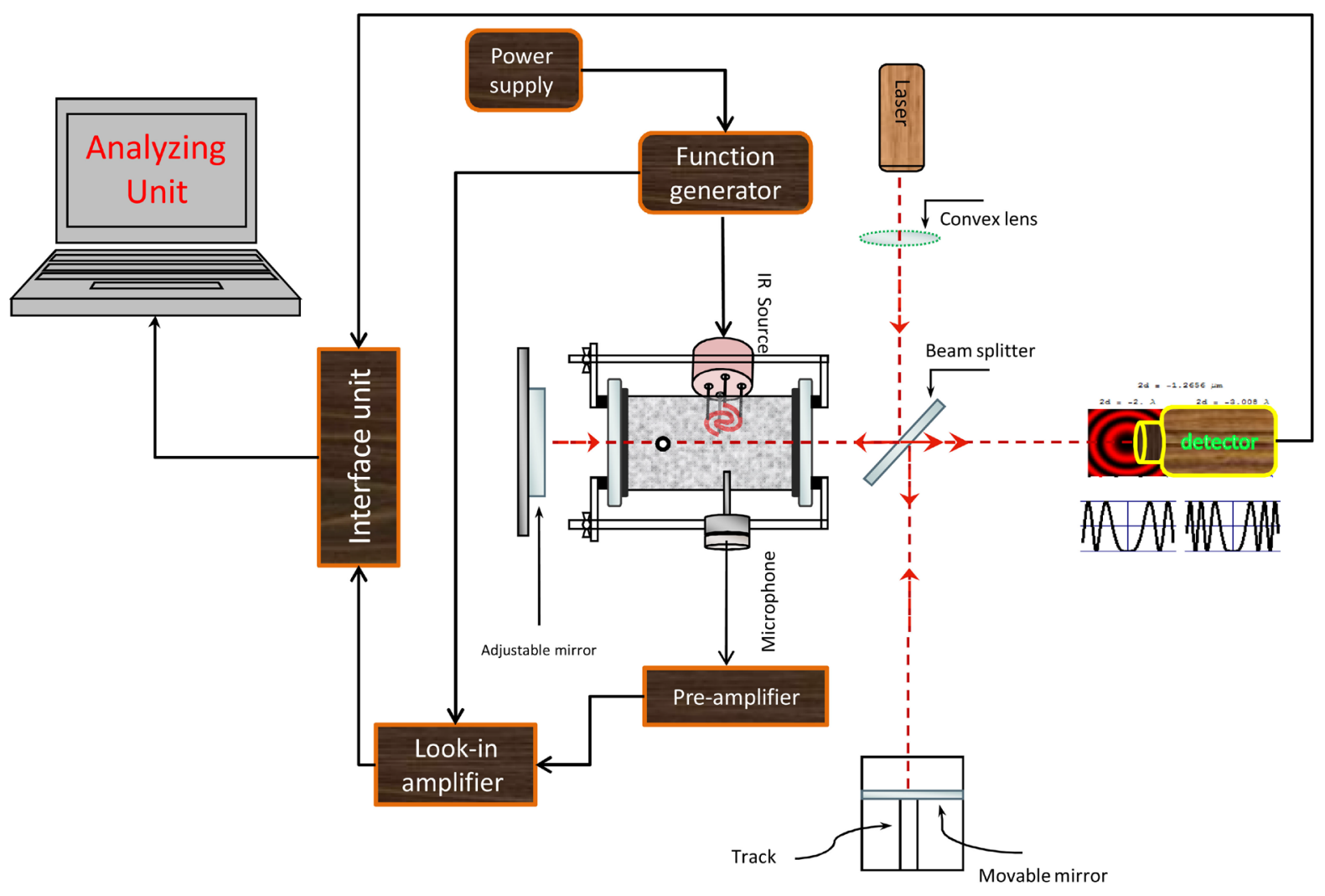

Figure 1. Schematic showing the combined Michelson-photoacoustic detection system.

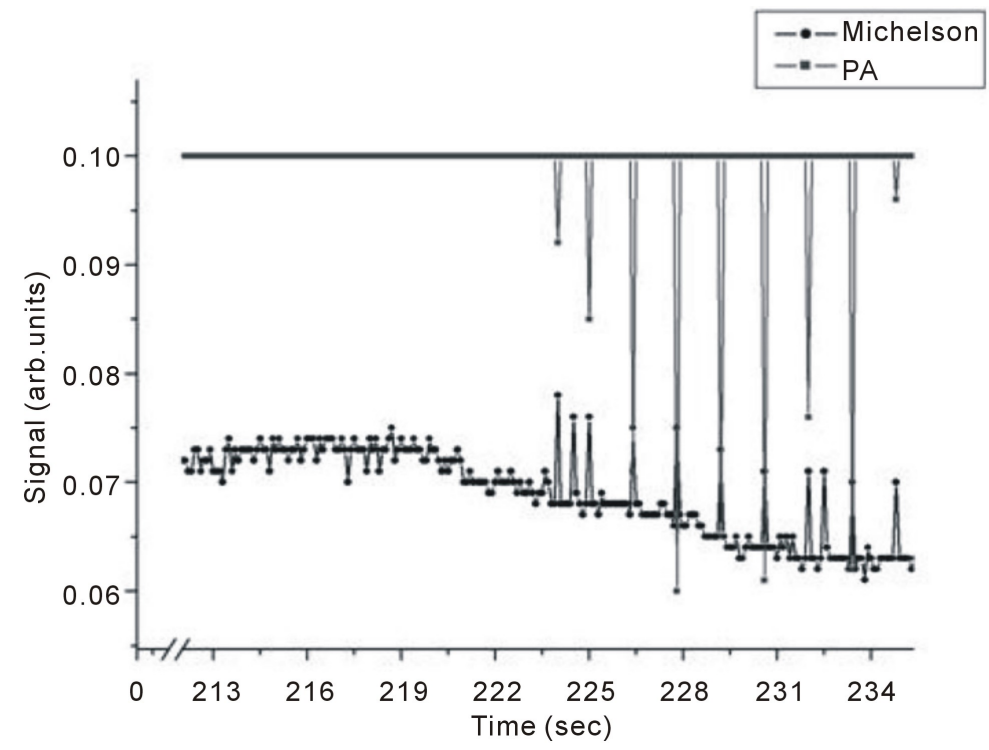

Figure 2. Simultaneous detection of PA and Michelson's signals for Chloroform $\left(\mathrm{CHCl}_{3}\right)$.

Simultaneous Michelson-PA signal detection aim at understanding the relationship between the signals initiated from direct change of index of refraction in the cell and detected as a fringe shift in and that produced by Infrared radiation absorption of trace gas in the chamber. Our focus is on wither the fringe shift is due to IR absorption in the range $400-8000 \mathrm{~cm}^{-1}$ by trace gases released in the chamber, or is it due to change in index of refraction 
resulting from increased level of released trace gases in the chamber. In all results to follow, although detection was simultaneous, the results of same sample were drawn on the same figure for sake of comparison.

Chloroform usually absorbs in the range $3100-650 \mathrm{~cm}^{-1}$, IR absorption by chloroform molecules is attributed to the type of motion atoms engaged in through vibrational stretching or bending of the chemical bonds and so, an individual bond is capable of absorbing more than one IR frequency. The fundamental frequencies at which chloroform absorbs in the gas phase are 3034, 1221, 769 and $681 \mathrm{~cm}^{-1}$. These frequencies were attributed to C-H stretching, C-H bending, C-Cl stretching and C-Cl bending respectively [27]. The intensity of some signal height due to IR absorption can be described as weak, medium, strong, variable and or broad. Both C-H stretching and bending in chloroform reach strong intensities, the signal is sharp for bending and broadened for stretching. C-Cl stretching level has higher intensity than both $\mathrm{C}-\mathrm{H}$ stretching and bending. Meanwhile, $\mathrm{C}-\mathrm{Cl}$ bending intensity is very low compared to the other modes. Figure 2 shows, that allowing some time for the liquid sample to evaporate, i.e. $\sim 223 \mathrm{~s}$ for the case of chloroform, both PA and Michelson signals appear and there is almost one to one signal correspondence for both techniques. Before that time, Michelson signal showed response at almost the noise level due to the gradual increase of index of refraction resulting from continuous liquid evaporation. When trace gases pressure reaches a level enough to initiate a PA signal, an alternating pressure source occurs. This is also detected by the Michelson technique, although it is more pronounced by PA technique. An important note worth mentioning at this point is that the Michelson method responded to all changes in the cell, while PA signal is selective to line absorption only.

Other liquids and seeds and or plant parts for example, leaves or flower samples were investigated, for the following: Mint, Jasmine, Anise and Nigella Sativa. The samples were bought from local shops and claimed to be from crop of the year of experiment. Fresh plant parts, from where some of the above-mentioned essential oils are usually extracted, were taken directly from the garden at the same day of investigation. The main idea is to test our system's ability to detect gas traces of different samples using PA technique compared with Michelson fringe signals, to judge closely detection ability of PA versus Michelson method and its future use as a monitor of trace gas detection. When, liquid sample is inserted into cell, its evaporation is enhanced by the pulsed IR radiation falling on it from the miniature wideband source. The evaporation rate depends on the volatility of the sample itself, and hence results were taken over different periods of time depending on type of sample under investigation. In all tested samples, the same amount by weight of essential oil and plant part were used, to allow easy comparison. Unless, otherwise specified $0.1 \mathrm{gm}$ of plant part and $4 \mu \mathrm{l}$ of the oil were introduced in the cell at the corresponding experiment. The intention from the set of experiments including the essential oil and the corresponding plant part from which the oil produced is to correlate the released gas traces from plant part to its oil counterpart, to form the basis of an experiment that assign the optimum harvest time, i.e. when signal from the plant part is optimum.

Pure jasmine oil and flower petals were both investigated for trace gas detection. Results are given in Figure 3 and Figure 4 for both techniques. It is noticed that for each signal of oil there is a corresponding signal from jasmine flower for both techniques. The level of OA signals are higher than those obtained by the Michelson's fringe signal.

Strong absorption spectrum intensities for the flower are related to strong trace release and the existence of water molecules, since water is a good absorber of infrared radiation especially at $3657,3755,1594 \mathrm{~cm}^{-1}$ in the gas phase [28].

Similarly, Michelson's fringe signals for mint oil and leaves versus evaporation time are tested and their results shown in Figure 5 and Figure 6. Two evaporation times investigated, it is noticed that allowing longer evaporation times for this particular sample leads to higher level signals.

It is noticed for PA signal for mint oil and leaves as shown in Figure 7, that for one spectrum the signal for mint leaves does not show.

Samples of $1 \mathrm{gm}$ of Nigella Sativa seeds and $4 \mu \mathrm{l}$ of Nigella Sativa oil were tested for trace gas detection. Figure 8 and Figure 9 show Michelson's fringe and PA signals for Nigella Sativa oil and seeds respectively over different evaporation time periods. Note that, signals from both techniques might not be taken at the same range of time, since as far as PA signal is concerned which is dependent on IR absorption in the range of source emission, i.e. 2 - $15 \mu \mathrm{m}$, waits for the appearance of trace gas.

In Figure 9, it is noticed for the first line that the corresponding seed line is missing and for oil sample that the last line is missing. This indicates that trace material is not available in both samples.

This effect is also noticed in Figure 10 at higher range of evaporation time. 


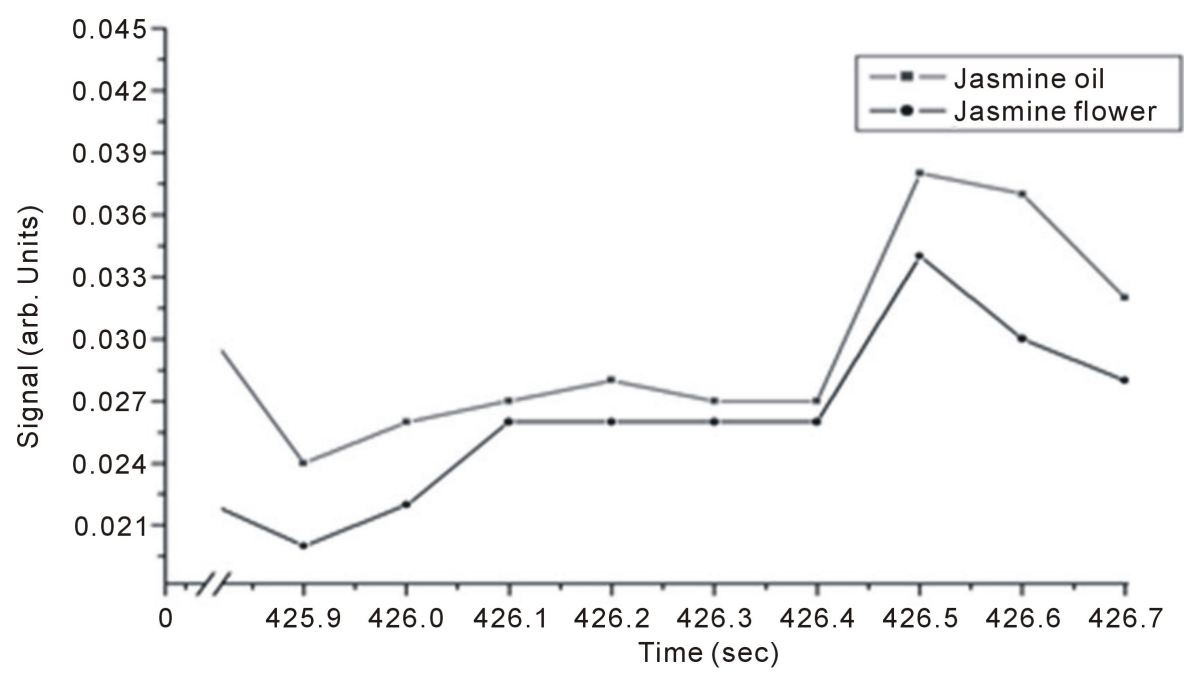

Figure 3. Simultaneous detection of PA and Michelson's signals for Chloroform $\left(\mathrm{CHCl}_{3}\right)$.

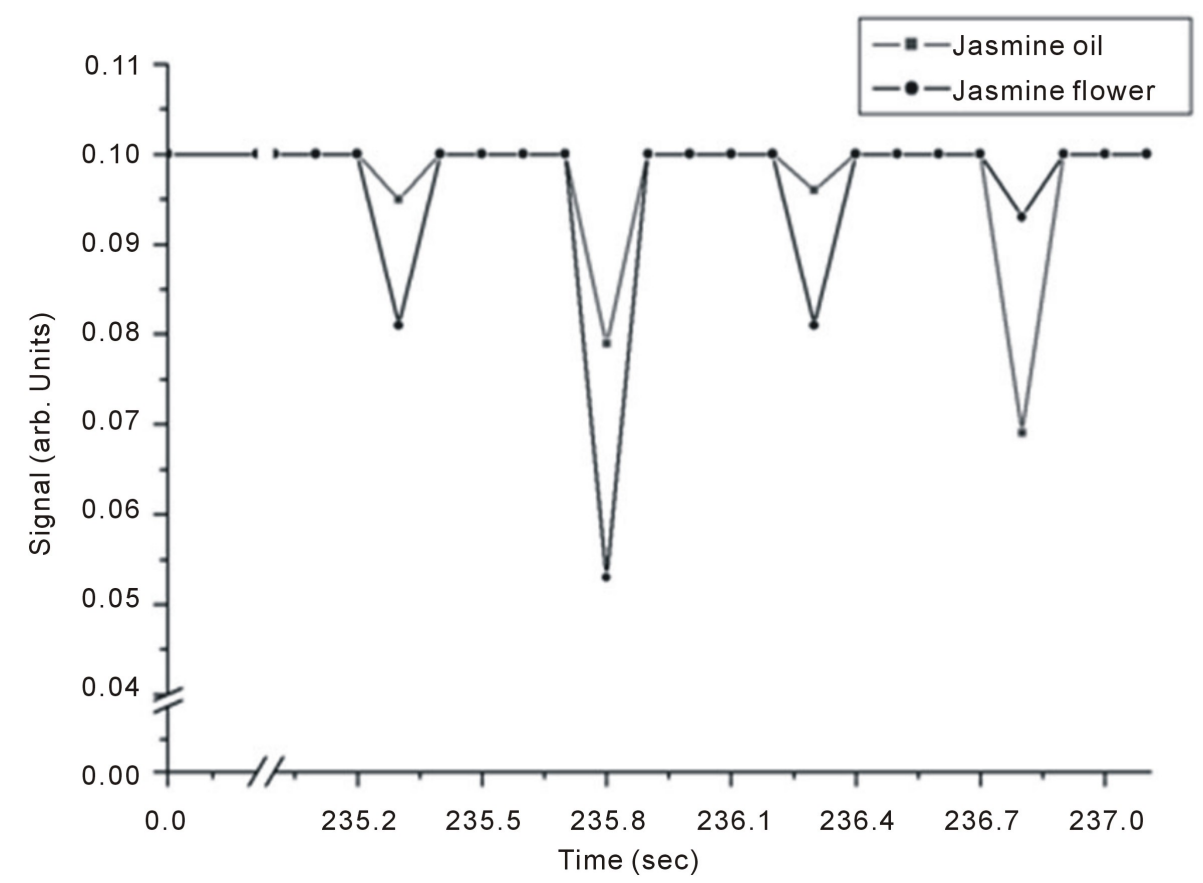

Figure 4. Intra Michelson’s cavity, PA signals for jasmine oil and flower.

In the case of Nigella Sativa, the seeds are the source of the oil, the rate of trace gas released from seeds is expected to be lower than that for the oil. This leads to the prediction that the oil absorption signal will reach higher level earlier than that of the seeds due to both reasons.

Anise oil (Pimpinella anisum) or sweet cumin, containing about $1 \%-4 \%$ volatile oil of which $72 \%-90 \%$ is trans-anethole, it has vast applications in food stuff, medicine and remedies. Anise seeds and oil samples results are shown in Figure 11 which shows Michelson's fringe signal and Figures 12-14 shows the PA signals.

It is noticed that signals of anise oil lags those of the seeds in Figure 12, but the opposite happens at longer evaporation times, and the signals restore the normal behavior at even longer times as seen in Figure 14. This shift is explained to be the result of detection time lag and it might also be due to either one of the following reasons; the first, might be related to the probability of having two different molecules absorbing IR radiation at very close frequencies. This hypothesis can be explained as follows, using the C-H stretching in both Alkane and Alkene as 


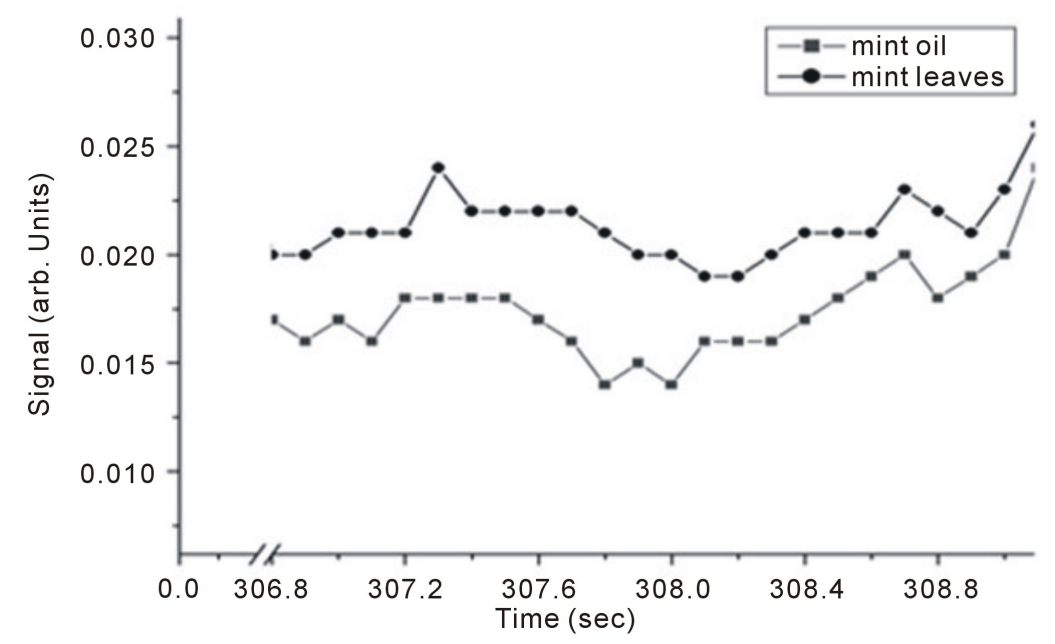

Figure 5. Detected Michelson’s fringe signals for mint oil and leaves samples.

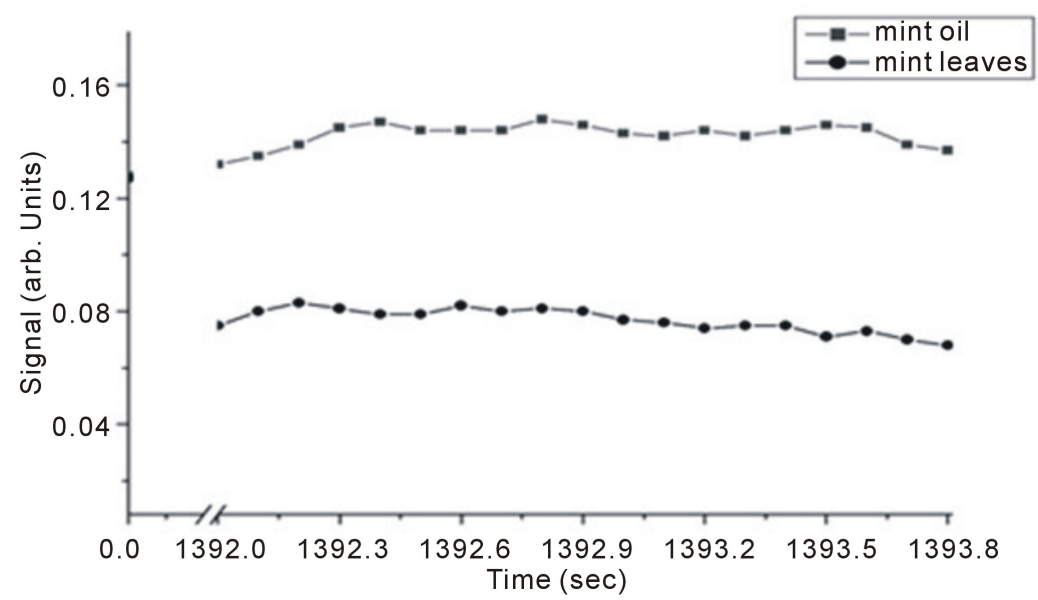

Figure 6. Michelson's method detected fringe signals for mint oil and leaves.

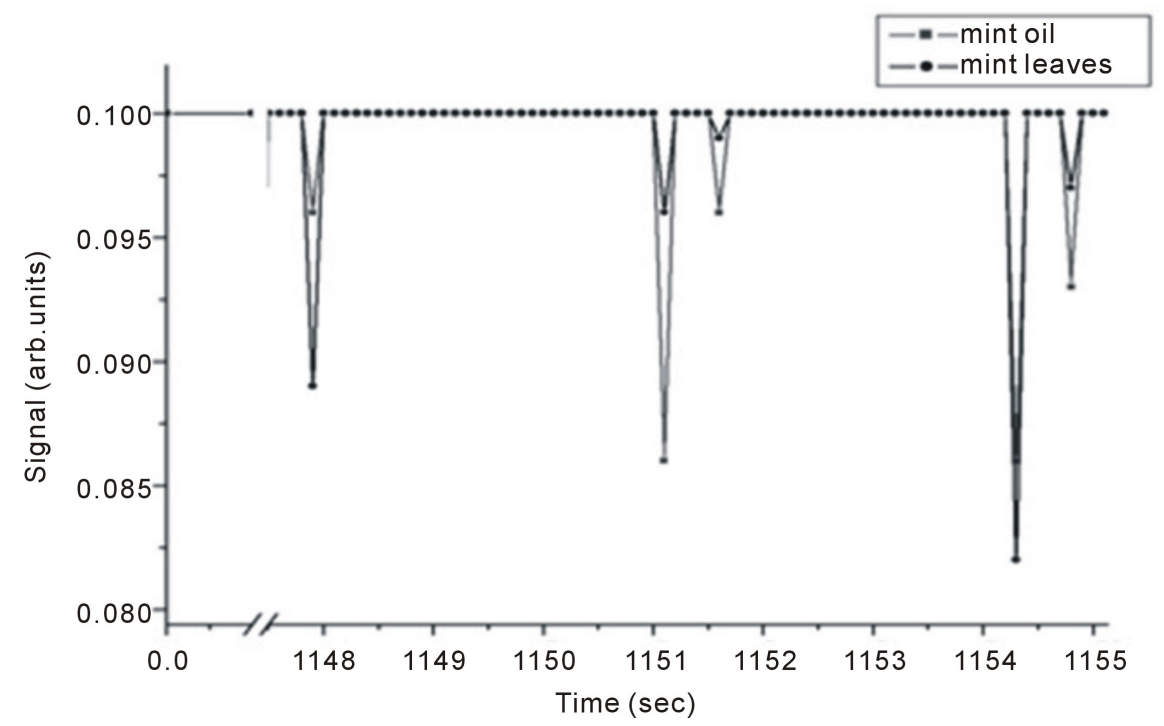

Figure 7. Michelson's method detected fringe signals for mint oil and leaves. 


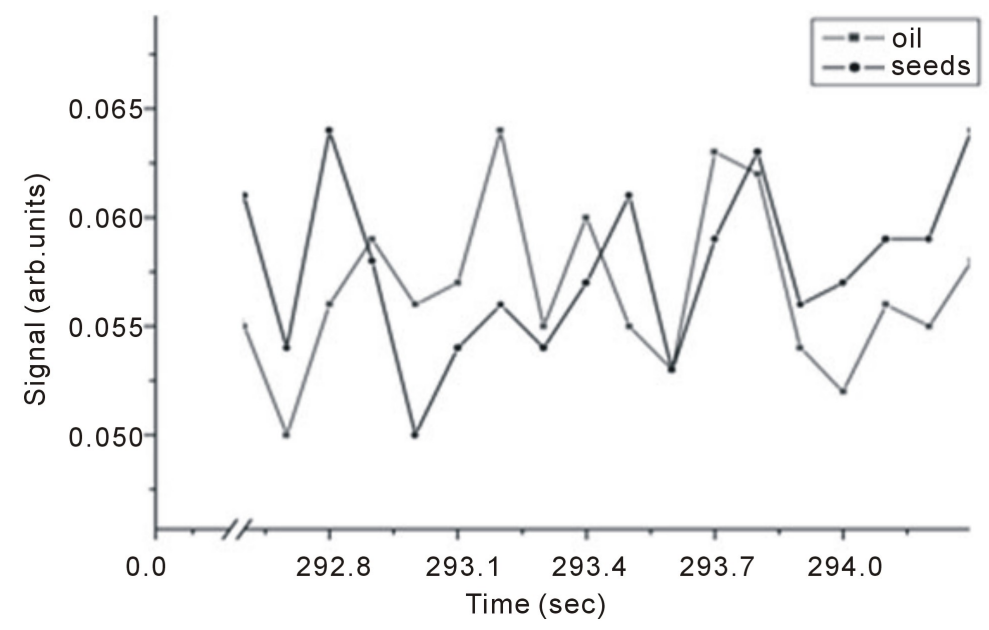

Figure 8. Michelson's fringe signals for Nigella Sativa seeds and oil versus evaporation time.

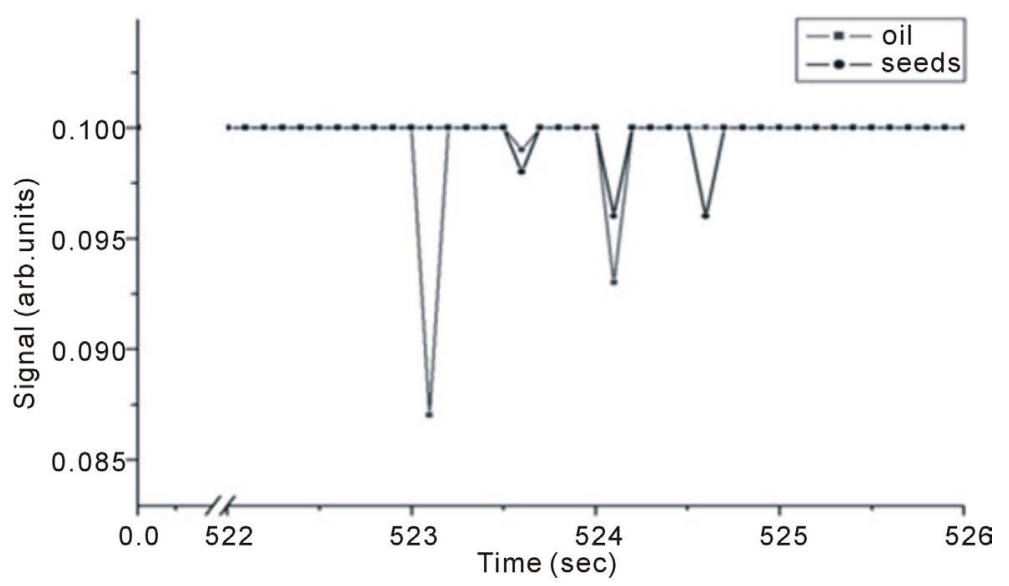

Figure 9. Intra Michelson's cavity PA signals for Nigella Sativa oil and seeds versus evaporation time.

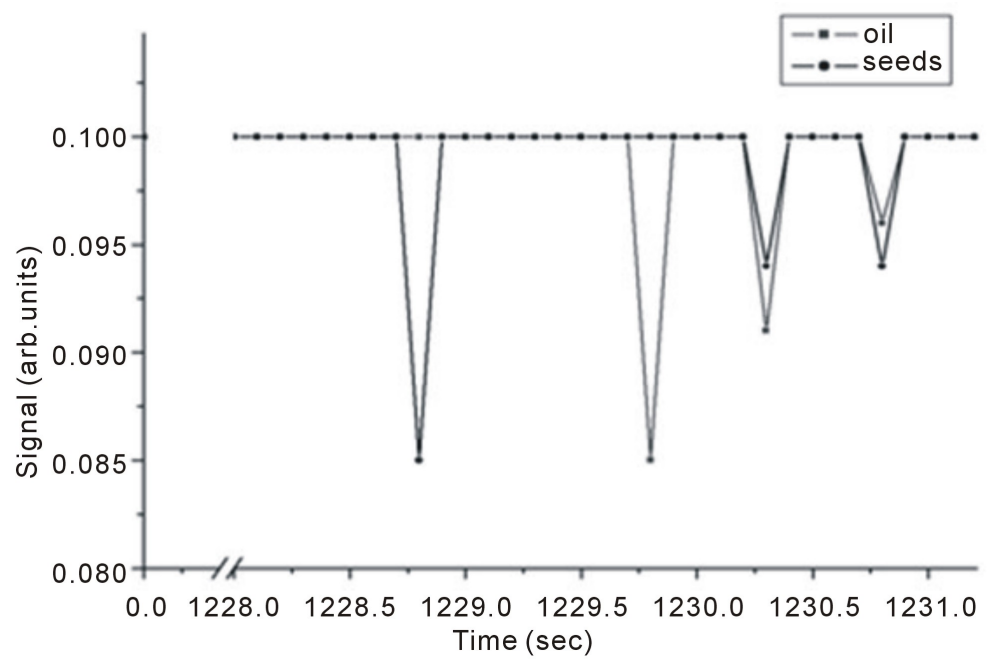

Figure 10. Intra Michelson's cavity PA signals for Nigella Sativa oil and seeds. 


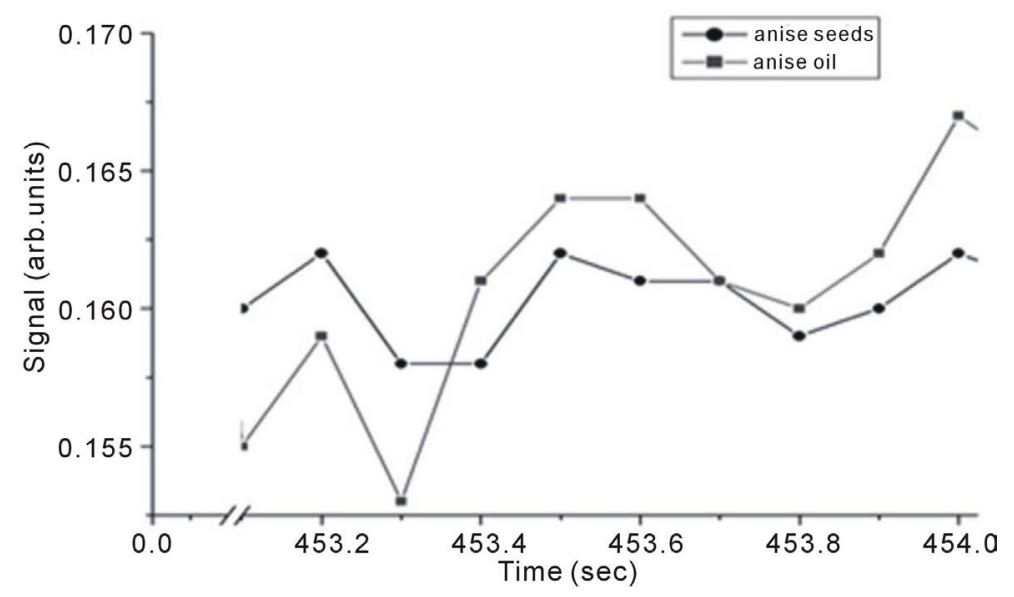

Figure 11. Michelson's fringe signals for anise seeds and oil versus evaporation time.

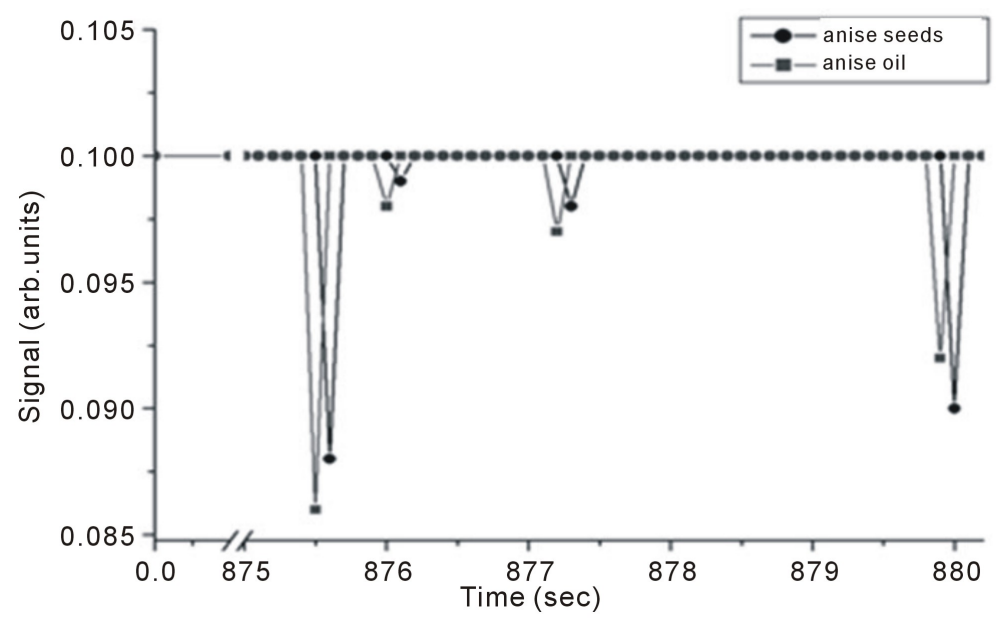

Figure 12. Intra Michelson's cavity PA signals for anise oil and seeds versus evaporation time.

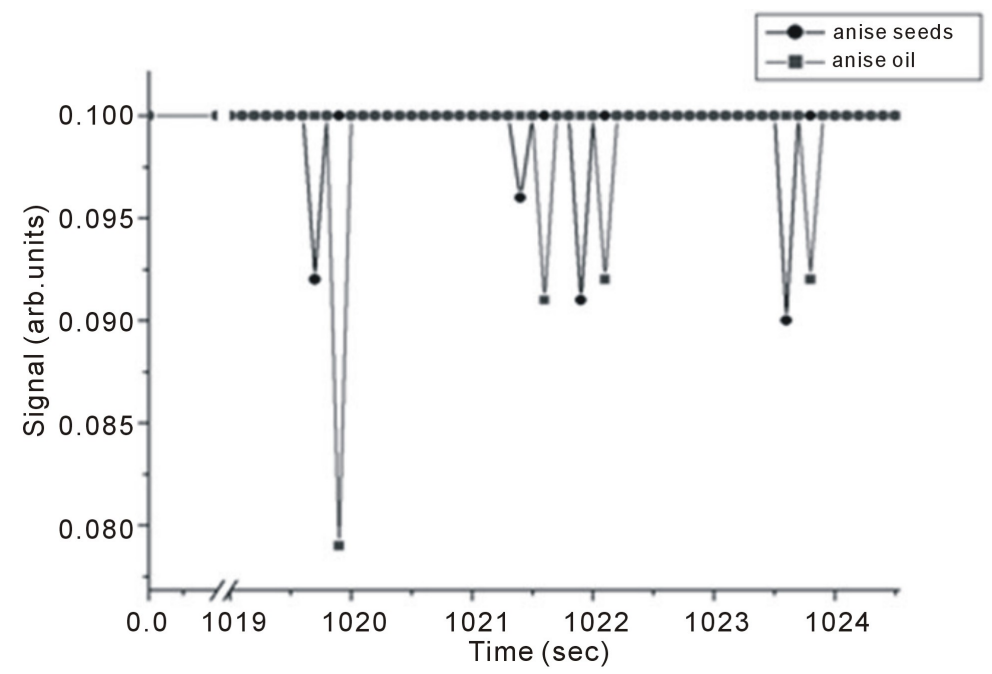

Figure 13. Intra Michelson's cavity PA signals for anise oil and seeds versus evaporation time. 


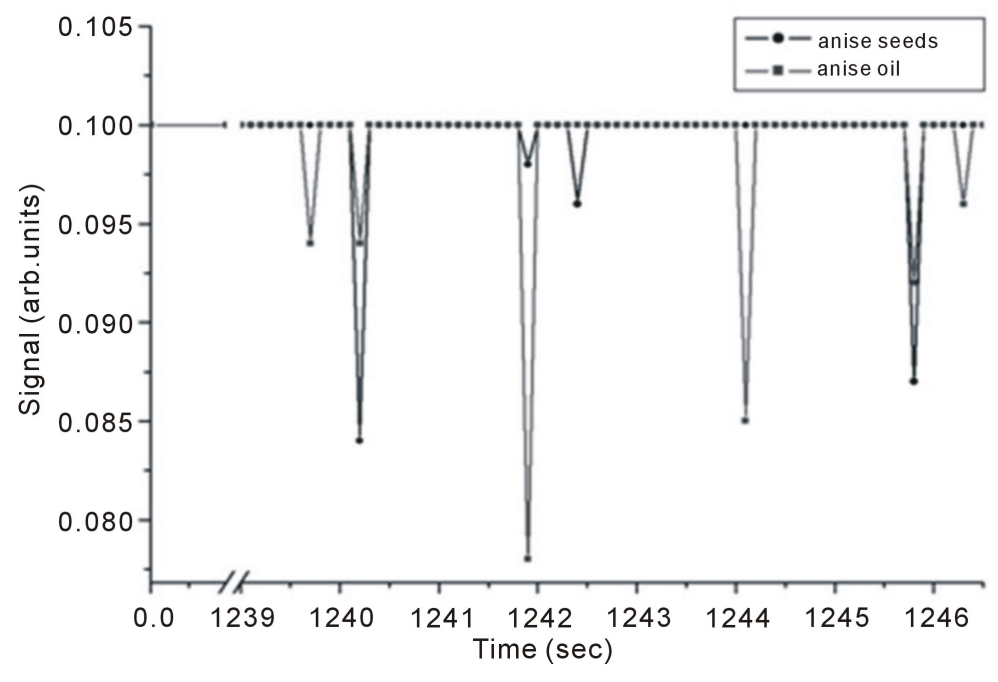

Figure 14. Intra Michelson's cavity PA signals for anise oil and seeds versus evaporation time.

an example: Alkanes reach their highest C-H stretching characteristic absorption frequency at $\sim 2960 \mathrm{~cm}^{-1}$, while Alkenes reach their lowest C-H stretching characteristic absorption frequency at $\sim 3000 \mathrm{~cm}^{-1}$ [29]. The second reason, might be related to the vibrating bonds in the absorbing compounds in one of the two traces attached to one isotopic atom leaving it to vibrate at a slower frequency compared to the same bond in the same compound in the trace of the other sample that has no isotopic atoms. An example of this is the shift occurred in the spectra of deuterated chloroform $\mathrm{CDCl}_{3}$ relative to chloroform $\mathrm{CHCl}_{3}$ [27].

It is obvious that both signals are of the same origin. IR absorption by gas molecules leads to thermal expansion through the nonradiative process which in turn results in the pressure fluctuations being detected by the microphone as the PA signal. During the thermal expansion process, heat deposition within the sample results in slight gradient changes in its refractive index forcing the fringes to a slight shift, which is being detected as Michelson's fringe pattern signal.

The presence of some peaks in flower spectra that are not shown in the corresponding oil sample is attributed to many other molecules like water present in the trace of flowers but not in that of pure oil. Different peaks in the spectra of oil are the result of different absorbing components that oil contains. Since the composition of each essential oil is usually been dominated by one single compound, then signals corresponding to both traces are related to that dominant compound.

\section{Conclusion}

For the first time, photoacoustic signals have been successfully detected inside Michelson's interferometer cavity. Both Michelson's and PA signals are generated at the same time, meaning that they are in phase and having the same origin. Different peaks in the PA signal denote different signal intensities achieved by different stretching or bending modes. Results from the oil samples are compared with those of the plant part where the oil is usually extracted; they show that they are related. This opens new research opportunity for results authentications by two separate techniques, i.e. correlation spectroscopy. It was successfully applied to distinguish between different samples due to band absorption of IR radiation in the range of 2 - $15 \mu \mathrm{m}$. Simultaneous detection of both signals using the new combined technique provides an alternative method to expensive lasers which is replaced by an inexpensive wideband-pulsed IR source with its good capabilities in the field of portable trace gas detection system. One last conclusion is that Michelson's method responded to all pressure changes in the cell, while PA is line absorption selective. It is concluded that if Michelson method is restricted to line selection only it achieves sensitivities higher than the famous sensitive PA techniques in the range of part per billion.

\section{References}

[1] Rosencwaig, A. and Pines, E. (1997) Biochimica and Biophysica Acta, 493, 10-23. 


\section{http://dx.doi.org/10.1016/0005-2795(77)90256-2}

[2] Kirkbright, G. and Miller, R. (1982) Analyst, 107, 798-802. http://dx.doi.org/10.1039/an9820700798

[3] Jenkins, T. (1985) Progress in Crystal Growth and Characterization of Materials, 11, 41-55.

[4] Meyer, P. and Sigrist, M. (1990) Review of Scientific Instruments, 61, 1779-1807. http://dx.doi.org/10.1063/1.1141097

[5] Bicanic, D., Zuidberg, B., Jalink, H., Miklos, A., Hartmans, K. and Van Es, A. (1990) Applied Spectroscopy, 44, 263265. http://dx.doi.org/10.1366/0003702904085426

[6] Schmidt, K. and Beckmann, D. (1998) Sensors and Actuators B, 51, 261-267. http://dx.doi.org/10.1016/S0925-4005(98)00229-9

[7] George, N., Paul, T., Radhakrishnan, P., Nampoori, V., Vallabhan, C. and Sebastian, M. (2000) Journal of Materials Science Letters, 19, 499-501. http://dx.doi.org/10.1023/A:1006701720030

[8] Szurkowski, J. (2001) Bulletin of Environmental Contamination and Toxicology, 66, 683-690.

[9] Yang, Y. and Zhang, S. (2003) Journal of Physics and Chemistry of Solids, 64, 1333-1337. http://dx.doi.org/10.1016/S0022-3697(03)00157-4

[10] Philip, A., Joseph, L., Irimpan, L., Krishnan, B., Radhakrishnan, P., Nampoori, V. and Natarajan, R. (2007) Physica Status Solidi, 204, 737-744. http://dx.doi.org/10.1002/pssa.200622287

[11] Bell, A.G. (1880) American Journal of Science, 20, 305-324. http://dx.doi.org/10.2475/ajs.s3-20.118.305

[12] El-Kahlout, A., Al-Jourani, M., Abu-Taha, M. and Laine, D. (1998) SPIE Proceedings, 3405, 578-583. http://dx.doi.org/10.1117/12.312811

[13] Herbert, S., Biel, K. and Vogelmann, T. (2006) Photosynthesis Research, 87, 287-294. http://dx.doi.org/10.1007/s11120-005-9009-9

[14] Besson, J., Schilt, S. and Thevenaz, L. (2008) Applied Physics B, 90, 191-196. http://dx.doi.org/10.1007/s00340-007-2821-5

[15] Michelson, A.A. and Morley, E.W. (1887) American Journal of Science, 34, 333-345. http://dx.doi.org/10.2475/ajs.s3-34.203.333

[16] Hecht, E. and Zajac, A. (1979) Optics. 1st Edition, Addison-Wesley Publishing Company Inc., Reading, 7-10, 320322.

[17] Fowles, G. (1989) Introduction to Modern Optics. 2nd Edition, Courier Dover Publications, 63-65.

[18] Steel, W. (1983) Interferometry. 2nd Edition, CUP Archive, 7-10.

[19] Bartusiak, M. (2000) Einstein's Unfinished Symphony. Joseph Henry Press, Washington DC, 27-28.

[20] Hariharan, P. (2006) Basics of Interferometry. 2nd Edition, Academic Press, 15-18.

[21] Kobayashi, T. and Misawa, K. (1997) Journal of Nuclear Materials, 248, 386-391. http://dx.doi.org/10.1016/S0022-3115(97)00176-1

[22] Gebbie, H. and Stone, N. (1964) Infrared Physics, 4, 85-92. http://dx.doi.org/10.1016/0020-0891(64)90014-4

[23] Genzel, L. and Kuhl, J. (1978) Infrared Physics, 18, 113-120. http://dx.doi.org/10.1016/0020-0891(78)90019-2

[24] Simeoni, D., Singer, C. and Chalon, G. (1997) Acta Astronautica, 40, 113-118.

[25] Montgomery, P., Montaner, D.D., Manzardo, O., Flury, M. and Herzig, H. (2004) Thin Solid Films, 450, 79-83. http://dx.doi.org/10.1016/j.tsf.2003.10.055

[26] Laine, D., Al-Jourani, M., Carpenter, S. and Sedgbeer, M. (1997) IEE Proceedings-Optoelectronics, 144, $315-322$. http://dx.doi.org/10.1049/ip-opt:19971361

[27] Kimoto, A. and Yamada, H. (1968) Bulletin of the Chemical Society of Japan, 41, 1096-1104. http://dx.doi.org/10.1246/bcsj.41.1096

[28] Chaplin, M. (2013) Water Structure and Science. http://www.lsbu.ac.uk/water/index2.html

[29] Stuart, B. (200) Infrared Spectroscopy: Fundamentals and Application. John Wiley \& Sons Ltd, Chichester, 77. 
Scientific Research Publishing (SCIRP) is one of the largest Open Access journal publishers. It is currently publishing more than 200 open access, online, peer-reviewed journals covering a wide range of academic disciplines. SCIRP serves the worldwide academic communities and contributes to the progress and application of science with its publication.

Other selected journals from SCIRP are listed as below. Submit your manuscript to us via either submit@scirp.org or Online Submission Portal.
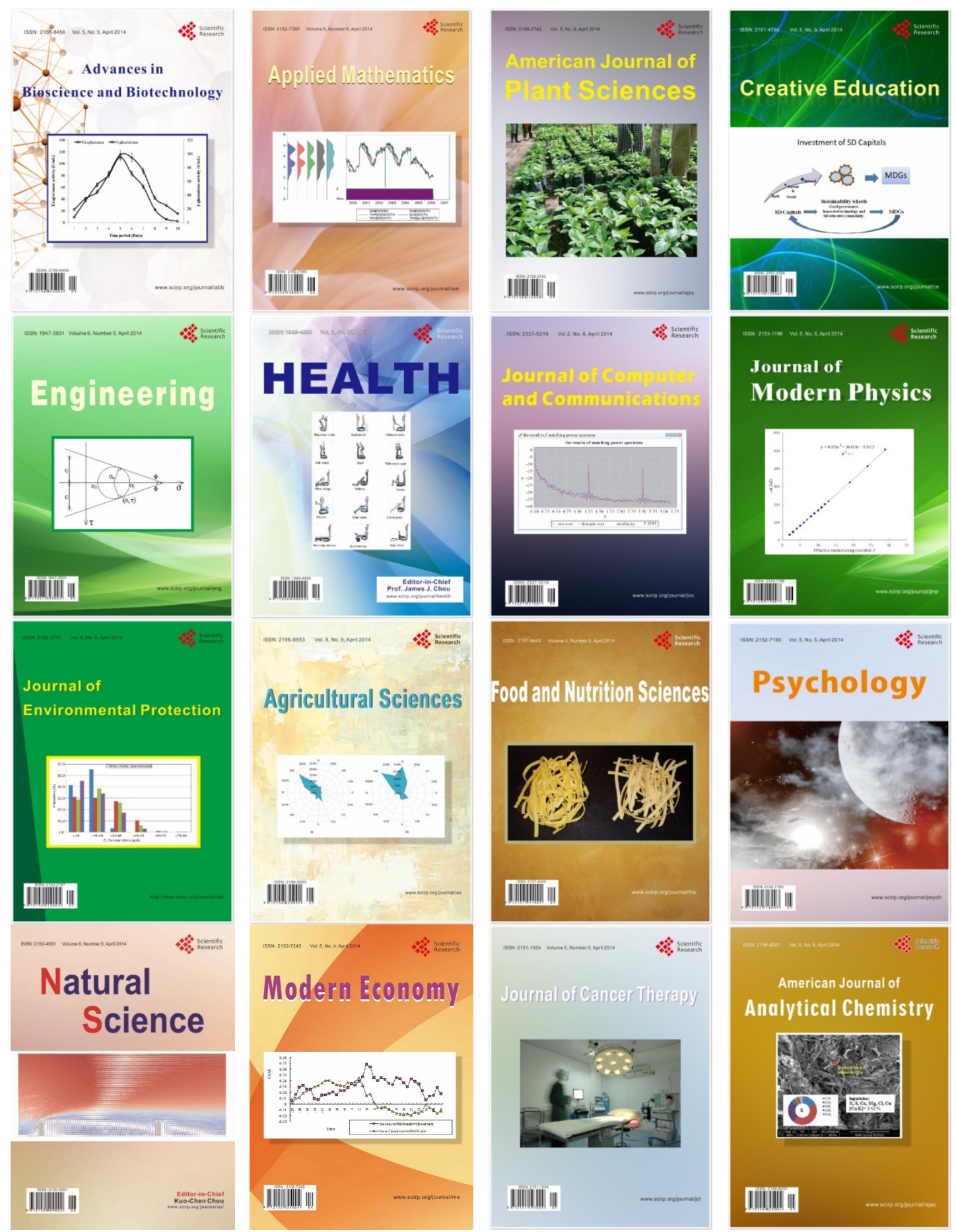